\title{
Magnetic Charcoal Supporting Silver as a Water Disinfectant
}

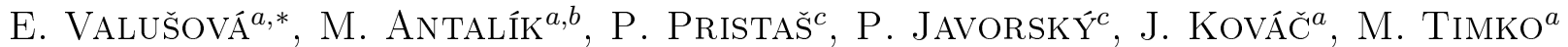 \\ ${ }^{a}$ Institute of Experimental Physics, Slovak Academy of Sciences, Watsonova 47, 04001 Košice, Slovakia \\ ${ }^{b}$ Department of Biochemistry, Faculty of Sciences, P.J.Šafárik University, Moyzesova 11, 04154 Košice, Slovakia \\ ${ }^{c}$ Institute of Animal Physiology, Slovak Academy od Sciences, Šoltésovej 4-6, 04001 Košice, Slovakia \\ We investigated the magnetic behavior of charcoal composite with incorporated magnetite and silver ions. \\ The magnetization curve measured at $282 \mathrm{~K}$ showed saturation magnetization of $8 \mathrm{emu} / \mathrm{g}$. By benefiting from \\ a mechanical process, the magnetic activated carbon, supporting silver ions (MCAG), acts as a magnetic filter \\ uptaking the bacteria. This idea was confirmed by the DGGE analysis in which the bacterial DNA was detectable \\ in the sediment after the treatment. \\ DOI: $10.12693 /$ APhysPolA.126.226 \\ PACS: 81.05.Ni, 75.60.Ej, 75.47.Lx, 81.05.U-, *92.40.qc
}

\section{Introduction}

Materials that contain nanomagnets have shown great potential for use in advanced applications because of their exceptional properties [1]. Of special interest are those materials that exhibit superparamagnetic behavior at room temperature. In groundwater treatment applications, the development of superparamagnetic composites has gained a considerable attention due to possible simplification of the separation process that normally involves complex and expensive procedures such as filtration or centrifugation. The possibility of low-cost production drives the scientific interest to this subject.

We introduced a novel procedure for the preparation of activated carbon (charcoal) composite in which magnetite nanoparticles are incorporated inside the pores of an activated carbon using a modified version of the approach which has been previously described in Ref. 2 . This material (denoted as MC) was then surface-modified with silver ions to bear antimicrobial properties for advanced applications, particularly the disinfection of surface water. Here we report combined properties of such final composites.

\section{General information}

The magnetite incorporated charcoals (MC) were prepared as reported previously [3]. The following batch adsorption of silver ions onto the MC was performed using a precise volume of silver nitrate solution as we published previously [3].

The magnetic properties of the MCAG were recorded at $282 \mathrm{~K}$ using a SQUID magnetometer (Quantum Design MpMS 5XL). The saturation magnetization was obtained from the magnetization curve registered in applied magnetic field of up to $6 \mathrm{~T}$.

\footnotetext{
*corresponding author; e-mail: valusova@saske.sk
}

The magnetic activated carbon, supporting silver ions (MCAG) was tested for the efficacy of removing bacteria from the river water samples along with water disinfection tests [3]. The total bacterial DNAs from river water samples and magnetic sediments were extracted using the Ultra Clean ${ }^{T M}$ Soil DNA kit (Mobio). The potential DNAs from magnetic supernatants were isolated by ethanol precipitation. All PCR reactions were carried as described previously [4]. The obtained $16 \mathrm{~S}$ rDNA fragments were subsequently used as templates for the second round of PCR, using specific bacterial primers GC-clamp-968f and 1401r. The cycling conditions were applied as already mentioned [4]. PCR products generated with GC-968f and 1401r primers were subjected to DGGE analysis performed by using DCode ${ }^{T M}$ Universal Mutation Detection System (Bio-Rad). The total volume of $45 \mu \mathrm{l}$ samples were loaded onto $8 \%(\mathrm{w} / \mathrm{v})$ polyacrylamide gel (40\% Acrylamide-Bis 37.5:1) in $1 \times$ TAE (40 mM Tris, $20 \mathrm{mM}$ acetate, $1 \mathrm{mM}$ EDTA) containing a linear denaturing gradient ranging from 30-60\% denaturant $(100 \%$ denaturant solution consists of $7 \mathrm{M}$ urea and $40 \%$ formamide). Electophoresis was run for $17 \mathrm{~h}$ at a constant voltage of $50 \mathrm{~V}$ and the temperature of $60{ }^{\circ} \mathrm{C}$. After the electrophoresis, the gel was incubated for $20 \mathrm{~min}$ in ethidium bromide $(0.5 \mu \mathrm{g} / \mathrm{ml})$, rinsed for $20 \mathrm{~min}$ in distilled water, and photographed with UV transillumination using Gel Logic Imaging System.

\section{Results and discussion}

The activated carbon with incorporated magnetite composites (MC) are excellent adsorbents. Their adorptivity is high, thus allowing progressive binding of silver ions [3]. The resulting MCAG composite possess stability against $\mathrm{Ag}^{+}$leaching [3] and can be adopted for further studies. We assumed previously that the MCAG bearing $20 \%$ sorbed $\mathrm{AgNO}_{3}$ (w/w) is stable, non-toxic [3] and thus is applicable for the following studies.

In order to prove the magnetic behavior of MCAG composites, the measurement of magnetization versus applied magnetic field was performed at room temperature. 


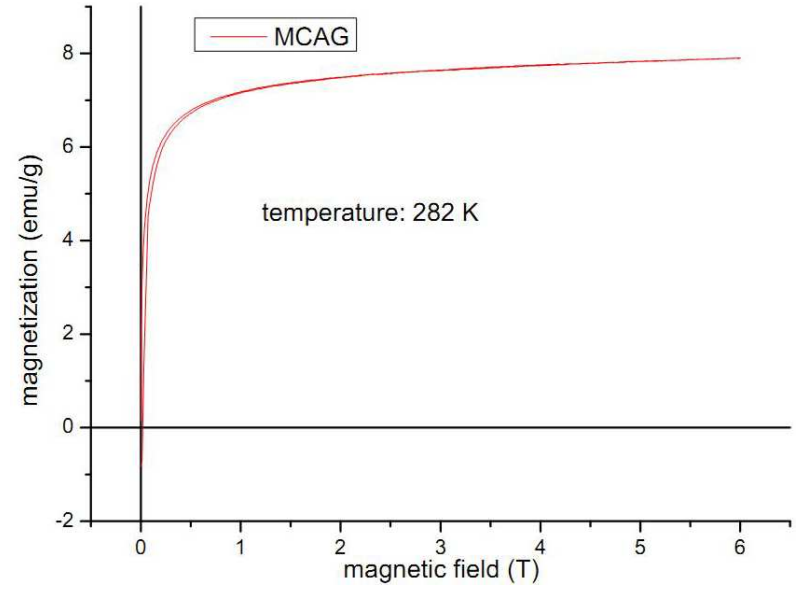

Fig. 1. Magnetization vs. applied field curve at $282 \mathrm{~K}$ for the magnetite incorporated onto charcoals bearing silver ions (MCAG).

The obtained magnetization curve, presented in Fig. 1, is dependent on the magnitude of the applied field. The saturation magnetization obtained from this dependence is $8 \mathrm{emu} / \mathrm{g}$ at $282 \mathrm{~K}$ and $6 \mathrm{~T}$. The saturated shape of the curve reflects the superparamagnetic-like behavior of MCAG. The obtained value of saturation magnetization is less than that $34 \mathrm{emu} / \mathrm{g}$ for bare magnetite nanoparticles with ultrafine nature [5], prepared in a same manner as for MCAG [3]. A smaller magnetization value is comparable to that published previously by Fuertes group [1]. A decrease of magnetic susceptibility has previously been attributed to residing of major magnetite nanoparticles inside the pores [1].

The antimicrobial capabilities of the prepared MCAG were previously [3] examined using water disinfection test. The bacterial counts in the river water samples $\left(1 \times 10^{3}\right.$ to $\left.1 \times 10^{5}\right)$ which were treated for 30 min using $1 \mathrm{~g} \cdot \mathrm{l}^{-1}$ of MCAG at room temperature, were reduced by five orders of magnitude. Thus, the removal of all bacteria from the surface water samples is a consequence of suggested mechanical process, in which positively charged surfaces of MCAG were able to attract negatively charged bacteria with subsequent disruption of bacterial membrane [3]. The unambiguous destruction of bacterial cells by MCAG was confirmed by DGGE analysis of the whole microbial community of river water including unculturable bacteria. The spectrum of the PCR amplified DNA fragments from the river water, treated supernatant and magnetic sediment samples is shown in the Fig. 2. A part of bacteria is lysed already during the 30 min treatment period (Fig. 2, line 3 - supernatant). Many species were eliminated. On the other hand, the spectrum of $16 \mathrm{~S}$ rRNA genes in the magnetic sediment indicates that sediment of treated water sample involved huge DNAs, probably from live and died bacteria (Fig. 2, line 2 - magnetic sediment). This method documented the efficiency of MCAG treatment of the surface river water, despite the presence in water of a complex microbial community.

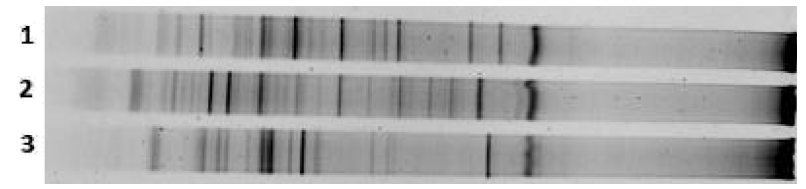

Fig. 2. DGGE patterns of $16 \mathrm{~S}$ rRNA gene fragments amplified with the primers $1401 \mathrm{r} / 968 \mathrm{f}-\mathrm{GC}$ from DNA templates, extracted from bacterial species presented in river water sample (1), sediment (2) and supernatant (3) after 30 min. treatment with MCAG.

\section{Conclusions}

The activated carbon with incorporated magnetite and silver ions (MCAG) exhibited superparamagnetic properties. These allow MCAG to be separated easily with a permanent magnet from the water after the bactericidal effect has occurred, thus avoiding any adverse environmental effects. The combination of magnetic character and biocidal efficiency introduces MCAG as an excellent candidate for the simple ambulatory disinfection of surface water.

\section{Acknowledgments}

The authors wish to thank the Slovak Grant Agency for support through VEGA grants No. 2/0025/12, 2/0016/12, APVV grant No. APVV-0171-10 and the European Union Structural Funds under ITMS project codes 26220120021,26220120033 and 26220220061.

\section{References}

[1] A.B. Fuertes, P. Tartaj, Chem. Mater. 18, 1675 (2006).

[2] M. Koneracká, P. Kopčanský, M. Antalík, M. Timko, C.N. Ramchand, D. Lobo, R.V. Mhta, R.T. Upadhyay, J. Magn. Magn. Mater. 201, 427(1999).

[3] E. Valušová, A. Vandžurová, P. Pristaš, M. Antalík. P. Javorský, Water Sci. Technol. 66, 2772 (2012).

[4] A. Vandžurová, P. Backor, P. Javorský, P. Pristaš, Vet. Microbiol. 164, 116 (2013).

[5] A.P.A. Faiyas, E.M. Vinod, J. Joseph, R. Ganesan, R.K. Pandey, J. Magn. Magn. Mater. 322, 400 (2010). 